\title{
The Effect of Polydeoxyribonucleotide on Chronic Non-healing Wound of an Amputee: A Case Report
}

\author{
Junho Shin, MD, Gahee Park, MD, Junhee Lee, MD, Hasuk Bae, MD, PhD
}

Department of Rehabilitation Medicine, Ewha Womans University College of Medicine, Seoul, Korea

\begin{abstract}
Polydeoxyribonucleotide (PDRN) is safe and effective in wound healing, cellular growth, synthesis of extracellular matrix protein, and inflammation reduction via activation of adenosine A2 receptors. We report a 28 -year-old male patient treated with PDRN injections for chronic non-healing wound refractory to negative pressure wound therapy, skin graft, or growth factors. Three injections of PDRN were administered at the wound site into the anterior and medial sides of the left stump on the 1st, 4th, and 9th days of hospitalization. The PDRN ameliorated wound healing by enhancing cell growth, tissue repair, and angiogenesis. PDRN application represents a potential treatment for non-healing wounds obviating the need for additional therapies, and hospitalization, as well as improve patient's activities of daily living.
\end{abstract}

Keywords Amputees, Wound healing, Polydeoxyribonucleotides

\section{INTRODUCTION}

Polydeoxyribonucleotide (PDRN), a substance derived from Oncorhynchus mykiss (Salmon trout), is a combination of purine and phosphodiester bonds constituting a pyrimidine nucleotide monomer. In a previous study, PDRN accelerated wound healing and improved angiogenesis by increasing the synthesis of vascular endothelial growth factor (VEGF) binding to adenosine A2 receptors $[1,2]$. It also improved blood supply and perfusion to the wound. Inadequate perfusion is an important factor in impaired wound healing. In a previous study, PDRN improved angiogenesis in patients with peripheral artery disease, diabetic ulcers, and pressure ulcers [3]. In addition, a PDRN injection represents a safe option for such patients with no side effects $[1,4,5]$.

Chronic non-healing wounds fail to heal spontaneously within 3 months [6]. They affect $2 \%$ of the American population [7] and entail an estimated more than $\$ 3$ billion in treatment costs per year [8]. Due to complications such as severe pain, septicemia, and hospitalization resulting from non-healing wounds, rapid treatment is important

Received August 12, 2017; Accepted September 18, 2017

Corresponding author: Hasuk Bae

Department of Rehabilitation Medicine, Ewha Womans University College of Medicine, 1071 Anyangcheon-ro, Yangcheon-gu, Seoul 07985, Korea. Tel: +82-2-2650-6020, Fax: +82-2-2650-5175, E-mail: acebhs@gmail.com

ORCID: Junho Shin (http://orcid.org/0000-0002-2723-7441); Gahee Park (http://orcid.org/0000-0002-5133-2449); Junhee Lee (http://orcid.org/00000001-7722-9979); Hasuk Bae (http://orcid.org/0000-0003-0508-3696).

(c) This is an open-access article distributed under the terms of the Creative Commons Attribution Non-Commercial License (http://creativecommons.org/ licenses/by-nc/4.0) which permits unrestricted noncommercial use, distribution, and reproduction in any medium, provided the original work is properly cited. Copyright ( 2018 by Korean Academy of Rehabilitation Medicine 
to improve the patient's quality of care.

In rehabilitation programs, fast functional recovery and fitting amputees with an early prosthesis improve the outcomes. In cases of delayed wound healing among amputees, complete wound closure is necessary for early prosthesis fitting. We report a case of an amputee who showed dramatic improvement in wound healing following PDRN injections.

\section{CASE REPORT}

A 28-year-old male patient with no significant medical history was diagnosed with a third-degree burn involving both lower extremities (10\%-19\% of body surface) following a car accident. Fasciotomy, irrigation, and debridement were performed to treat a third-degree burn on the left lower leg along with compartment syndrome. Both lower extremities were amputated due to persistent necrosis, despite several debridements for wound necrosis.

Below knee amputation was performed for the left lower extremity. A transmetatarsal amputation was performed for the right lower extremity. Negative pressure wound therapy (NPWT) was administered after application of a human acellular dermal allograft and split thickness skin graft. Since then, daily occlusive dressing using hydrophilic polyurethane foam and human basic fibroblast growth factor (bFGF) has been performed.

Debridement and ostectomy were performed due to necrosis and bone exposure after 1 month, despite on- going NPWT. After 2 months of partial wound improvement, the patient received a home care kit for NPWT and bFGF. Despite continuous application of allogenic keratinocytes for incomplete wound healing, the prosthesis was difficult to wear because of the open wound. Lack of wound closure and prosthesis limited not only gait training but also activities associated with daily living. The patient continued to receive wound care in the outpatient clinic and home care services using NPWT and bFGF.

After 7 months, the patient visited our outpatient department for stump management, prosthesis use, and gait training with the prothesis for bilateral amputation sites. Bone length (from greater trochanter to bony end) was $104 \mathrm{~cm}$ at the right lower extremity, and $69 \mathrm{~cm}$ at the left lower extremity. The left stump site was bulbous, and showed inflammation, including redness and swelling. The open wound measured $3 \mathrm{~cm} \times 2 \mathrm{~cm}$ on the anterior side and $3 \mathrm{~cm} \times 2 \mathrm{~cm}$ on the medial side. The patient felt 2-3 degrees of pain according to the numeric rating scale, and continuous tingling in both stump areas. In addition to active range of motion and strengthening exercises in the bilateral lower extremities, the patient received stump site massage, tapping, and slapping, wrapping, and friction rub of the residual limb for desensitization. Since the previous treatment for the stump wound deteriorated, we decided to proceed with PDRN treatment.

Injections (1 syringe, $2 \mathrm{~mL}$, for 3 times) of intradermal PDRN (Rejuvenex; PharmaResearch Products Inc., Seoul, Korea) into the open wounds on the anterior and medial
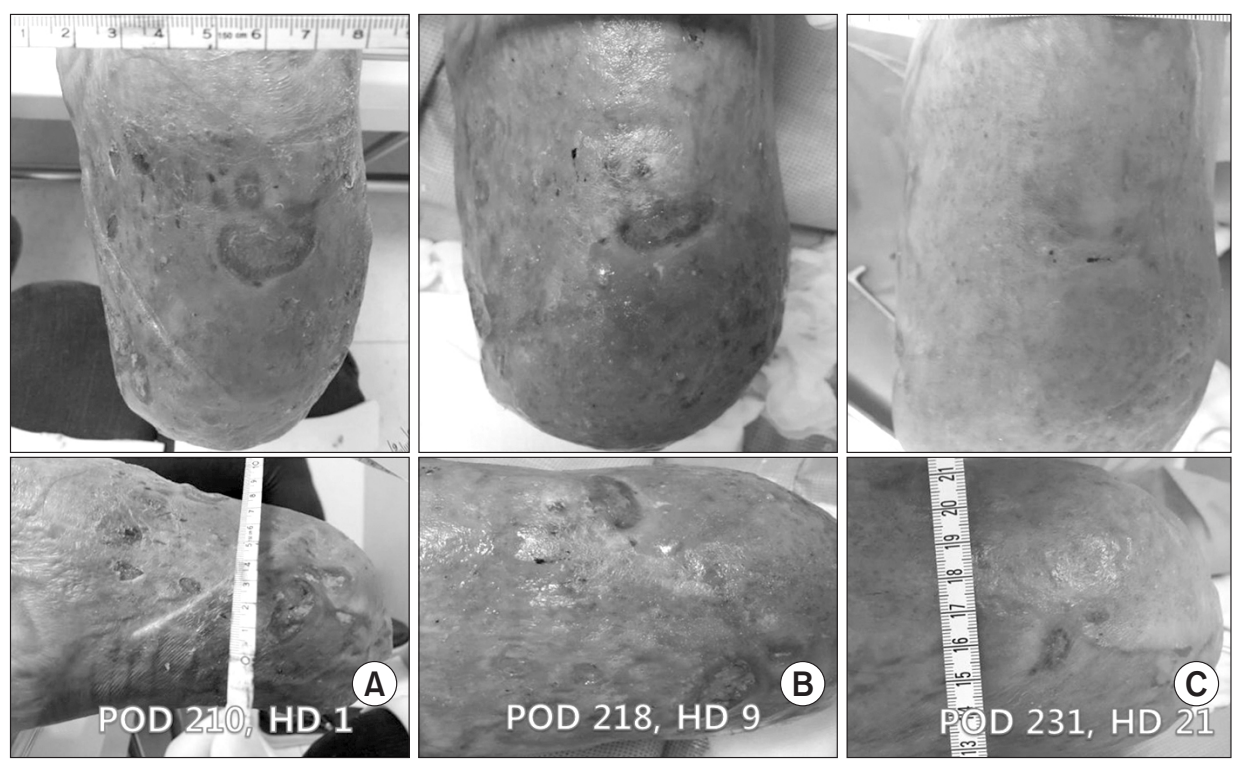

Fig. 1. Two open wounds existed on the left lower extremity during the first visit (A). Since the first polydeoxyribonucleotide (PDRN) injection on the wound area, wound closure occurred gradually. (B) After the second PDRN injection. (C) After the third PDRN injection. After 3 PDRN injections, almost full epithelialization occurred as shown. POD, postoperative date; HD, hospital day. 
side were administered to heal the left stump on the 1st, 4 th, and 9th days of hospitalization, along with a daily hydrophilic polyurethane foam dressing. After 3 weeks, full epithelization and improved skin tone were observed (Fig. 1). After 4 weeks of hospitalization, the wounds were improved adequately to wear the prosthesis (3-4 times, 1 hr/day).

After comprehensive rehabilitative treatment including gait training, the patient managed to walk independently.

\section{DISCUSSION}

We report the case of skin regeneration into musculoskeletal tissue using PDRN injections on refractory wounds in an amputee, which were caused by thirddegree burns with no improvement 7 months after flap surgery. To our knowledge, this is the first study demonstrating the role of PDRN application to a chronic open wound in an amputee. Chronic non-healing wounds warrant rapid and prompt treatment to diminish the risk of comorbidities such as infection and hospitalization. This case required especially quick wound management to allow for appropriate fitting of prosthesis to improve the patient's activities of daily living as well as his quality of life.

Autologous skin graft has been established as the standard therapeutic option for large-surface and deep wounds [9]. This patient carried two $3 \mathrm{~cm} \times 2 \mathrm{~cm}$-sized open wounds after a skin graft without experiencing a full recovery. Wound epithelization was difficult even after the application of NPWT, bFGF, and allogenic keratinocytes before the PDRN injections. The NPWT increased the dermal perfusion but had no direct effects on the capillary vessels, which actually mediated the skin perfusion. However, in a previous study, PDRN eventually improved the capillary density following improved angiogenesis by increasing VEGF production in skin when injected into skin [4].

In some patients, such as the case in point, PDRN was used when healing failed with conventional therapies. PDRN has advantages of non-invasiveness, simplicity, and without the need for any other medical equipment.

No hospitalization is needed for PDRN injections resulting in cost-effective and safe treatment outcomes. This study is consistent with previous studies that reported the positive effects of PDRN on wound healing, without any side effects $[1,4]$.

However, no standardized method of administering PDRN injections is available currently. Prospective and randomized controlled trials are required to show the efficacy of PDRN.

The application of PDRN is also an optional treatment for the closure of chronic non-healing wounds. These findings indicate that PDRN positively modulates the wound healing process in refractory wounds. Its use also improves the clinical outcomes of patients and lowers the need for additional therapies and hospitalization.

\section{CONFLICT OF INTEREST}

No potential conflict of interest relevant to this article was reported.

\section{REFERENCES}

1. Kim JY, Pak CS, Park JH, Jeong JH, Heo CY. Effects of polydeoxyribonucleotide in the treatment of pressure ulcers. J Korean Med Sci 2014;29 Suppl 3:S222-7.

2. Lee DW, Hong HJ, Roh H, Lee WJ. The effect of polydeoxyribonucleotide on ischemic rat skin flap survival. Ann Plast Surg 2015;75:84-90.

3. Bitto A, Polito F, Altavilla D, Minutoli L, Migliorato A, Squadrito F. Polydeoxyribonucleotide (PDRN) restores blood flow in an experimental model of peripheral artery occlusive disease. J Vasc Surg 2008;48:1292300.

4. Altavilla D, Bitto A, Polito F, Marini H, Minutoli L, Di Stefano V, et al. Polydeoxyribonucleotide (PDRN): a safe approach to induce therapeutic angiogenesis in peripheral artery occlusive disease and in diabetic foot ulcers. Cardiovasc Hematol Agents Med Chem 2009; 7:313-21.

5. Pang C, Ibrahim A, Bulstrode NW, Ferretti P. An overview of the therapeutic potential of regenerative medicine in cutaneous wound healing. Int Wound J 2017; 14:450-9.

6. Saltmarche AE. Low level laser therapy for healing acute and chronic wounds: the extendicare experience. Int Wound J 2008;5:351-60.

7. Sen CK, Gordillo GM, Roy S, Kirsner R, Lambert L, Hunt TK, et al. Human skin wounds: a major and snowballing threat to public health and the economy. 
Wound Repair Regen 2009;17:763-71.

8. Menke NB, Ward KR, Witten TM, Bonchev DG, Diegelmann RF. Impaired wound healing. Clin Dermatol 2007;25:19-25.

9. Insausti CL, Alcaraz A, Garcia-Vizcaino EM, Mrowiec
A, Lopez-Martinez MC, Blanquer M, et al. Amniotic membrane induces epithelialization in massive posttraumatic wounds. Wound Repair Regen 2010;18:36877. 